\title{
Appropriate treatment modality for solitary small hepatocellular carcinoma: Radiofrequency ablation vs. resection vs. transplantation?
}

\author{
Keun Soo Ahn and Koo Jeong Kang \\ Division of Hepatobiliary-Pancreatic Surgery, Department of Surgery, Keimyung University Dongsan Medical Center, Daegu, Korea
}

There has been controversy regarding the first-line treatment modality for the patients who have small solitary hepatocellular carcinoma (HCC); radiofrequency ablation (RFA) or percutaneous ethanol injection (PEI), surgical hepatic resection (HR) and liver transplantation (LT). For selection of treatment modality of HCC, it should be considered of hepatic reservoir function as well as the tumor stage. If the liver function is good enough, HR may be the first choice regardless of the tumor size. However, recent studies comparing RFA with resection showed comparable outcome and similar survival rates. RFA, HR and LT provide good outcome for patients who have small HCCs. RFA would be desired in patients who have below $3.0 \mathrm{~cm}$ in size and low alpha-fetoprotein $(<200 \mathrm{ng} / \mathrm{mL})$. However, in small HCC with high tumor marker, HR should be considered. Better patient selection for the 'resection first' approach and early detection of recurrence can achieve better outcomes of the salvage LT strategy. Another benefit of resection first strategy is that it make possible to do enlist of LT for patients before recurrence at high risk of HCC recurrence after resection on the basis of pathologic aggressiveness, microvascular invasion and/or satellites nodule. They should be applied appropriately according to the tumor size, location, tumor markers and underlying liver parenchymal disease. (Clin Mol Hepatol 2019;25:354-359)

Keywords: Hepatocellular carcinoma; Hepatectomy; Radiofrequency ablation; Liver transplantation

\section{INTRODUCTION}

There has been controversy regarding the most effective firstline treatment modality for the patients who have small solitary hepatocellular carcinoma (HCC) (tumor size of $2-5 \mathrm{~cm}$ ); radiofrequency ablation (RFA) or percutaneous ethanol injection (PEI), surgical hepatic resection (HR) and liver transplantation (LT). For choosing treatment modality of HCC, it should be considered according to the underlying liver parenchymal disease with function as well as the tumor stage. If the liver function is good enough, HR may be the first choice for the solitary HCC regardless of the tumor size. However, recent studies comparing RFA with resection showed comparable outcome and similar survival rates. LT offers an excellent long term outcome, addressing both the underlying liver disease as well as tumor stage. Herein, we reviewed the role of HR, RFA and LT for small sized HCC and would suggest updated new strategy to get the best short- and long-term outcome (Table 1, 2). ${ }^{1-10}$

\footnotetext{
Abbreviations:

DFS, disease-free survival; HCC, hepatocellular carcinoma; HR, hepatic resection LT, liver transplantation; MVI, microvascular invasion; PEl, percutaneous ethanol injection; RFA, radiofrequency ablation
}

\section{Corresponding author : Koo Jeong Kang}

Division of Hepatobiliary-Pancreatic Surgery, Department of Surgery, Keimyung University Dongsan Medical Center, 56 Dalseong-ro, Jung-gu, Daegu 41931, Korea

Tel: +82-53-250-7655, Fax: +82-53-250-7322

E-mail: kjkang@dsmc.or.kr

https://orcid.org/0000-0003-1385-8308 
Table 1. Advantage and disadvantage according to the treatment modalities

\begin{tabular}{lll}
\hline & Advantage & \multicolumn{1}{c}{ Disadvantage } \\
\hline Radiofrequency ablation & Minimal invasive & Lower rate of complete ablation \\
Hepatic resection & Longer survival & Invasive \\
& Complication rate is higher, but acceptable. \\
Liver transplantation & Best survival & Highly invasive, but well established, safe enough. \\
& Limitation of donor pool \\
\hline
\end{tabular}

Table 2. Summary of treatment modality in small hepatocellular carcinoma (HCC)

\begin{tabular}{|c|c|c|c|c|c|c|}
\hline & Study design & $\begin{array}{l}\text { Compare with } \\
\text { study population }\end{array}$ & Inclusion creteria & Survival outcome & Other outcome & Preference \\
\hline $\begin{array}{l}\text { Chen et } \\
\text { al. }{ }^{1}\end{array}$ & RCT & $\begin{array}{l}\text { RFA }(n=71) \text { vs. } \\
\quad H R(n=90)\end{array}$ & Solitary $\leq 5 \mathrm{~cm}$ & No difference & More complication at HR & $\begin{array}{l}\text { Prefer RFA to } \\
\text { HR }\end{array}$ \\
\hline $\begin{array}{l}\text { Huang et } \\
\text { al. }^{6}\end{array}$ & RCT & $\begin{array}{l}\text { RFA }(n=115) \text { vs. } \\
\quad H R(n=115)\end{array}$ & Within Milan criteria & $\begin{array}{l}\text { Better survival, lower } \\
\text { recurrence in HR }\end{array}$ & $\begin{array}{l}\text { Better survival in } \mathrm{HR} \text { for } \\
<3 \mathrm{~cm} \text { as well as }<5 \mathrm{~cm}\end{array}$ & $\begin{array}{l}\text { Prefer HR to } \\
\text { RFA }\end{array}$ \\
\hline $\begin{array}{l}\text { Feng et } \\
\text { al. }^{7}\end{array}$ & RCT & $\begin{array}{l}\text { RFA }(n=84) \text { vs. } \\
\quad H R(n=84)\end{array}$ & $\begin{array}{l}\mathrm{HCC} \leq 4 \mathrm{~cm} \\
\text { Up to } 2 \text { masses }\end{array}$ & No difference & $\begin{array}{l}\text { Multiple tumor and high } \\
\text { ICGR15 are poor risk } \\
\text { factors }\end{array}$ & $\begin{array}{l}\text { Prefer HR to } \\
\text { RFA }\end{array}$ \\
\hline $\begin{array}{l}\text { Hasegawa } \\
\text { et al. }\end{array}$ & $\begin{array}{l}\text { Retrospective } \\
\text { Nationwide } \\
\text { cohort }\end{array}$ & $\begin{array}{l}\text { RFA }(n=5,548) \text { vs. } \\
\operatorname{HR}(n=5,361) \text { vs. } \\
\text { PEI }(n=2,059)\end{array}$ & $\begin{array}{l}\text { No more than } 3 \text { tumors } \\
\text { and each tumor less } \\
\text { than } 3 \mathrm{~cm}\end{array}$ & $\begin{array}{l}\text { Better DFS and OS in } \\
\text { HR group than RFA } \\
\text { and PEl group }\end{array}$ & $\begin{array}{l}\text { RFA has better survival } \\
\text { outcome than that of } \\
\text { PEI }\end{array}$ & $H R>R F A>P E I$ \\
\hline $\begin{array}{l}\text { Fang et } \\
\text { al. }^{8}\end{array}$ & $\mathrm{RCT}$ & $\begin{array}{c}\text { RFA }(n=60) \text { vs. } \\
\quad H R(n=60)\end{array}$ & Solitary $\leq 3 \mathrm{~cm}$ & No difference & $\begin{array}{l}\text { Lower complication in } \\
\text { RFA }\end{array}$ & Prefer RFA \\
\hline $\begin{array}{l}\text { Huang et } \\
\text { al. }^{2}\end{array}$ & $\begin{array}{l}\text { Non } \\
\text { randomaized } \\
\text { prospective }\end{array}$ & $\begin{array}{l}\text { RFA ( } n=121) \text { vs. } \\
H R(n=225)\end{array}$ & Solitary $\leq 3 \mathrm{~cm}$ & No difference & $\begin{array}{l}\text { Better outcome of life } \\
\text { quality in RFA }\end{array}$ & $\begin{array}{l}\text { Prefer RFA to } \\
\text { HR }\end{array}$ \\
\hline Imai et al. ${ }^{9}$ & Retrospective & $\begin{array}{c}\text { RFA }(n=82) \text { vs. } \\
\quad H R(n=101)\end{array}$ & Solitary $\leq 3 \mathrm{~cm}$ & $\begin{array}{l}\text { Better OS and DFS in } \\
\text { HR for }<3 \mathrm{~cm}\end{array}$ & $\begin{array}{l}\text { No difference in } \leq 2 \mathrm{~cm} \\
\text { Better disease free and } \\
\text { overall survival in larger } \\
\text { than } 2 \mathrm{~cm}\end{array}$ & $\begin{array}{l}\text { Prefer HR in } \\
\text { larger than } \\
2 \mathrm{~cm}\end{array}$ \\
\hline Kim et al. ${ }^{5}$ & Case control & $\begin{array}{l}\text { RFA ( } n=152) \text { vs. } \\
\text { HR }(n=152)\end{array}$ & Solitary $\leq 3 \mathrm{~cm}$ & $\begin{array}{l}\text { Better DFS in HR than } \\
\text { RFA, no different OS }\end{array}$ & $\begin{array}{l}\text { Higher risk of treatment } \\
\text { site recurrence in RFA }\end{array}$ & $\begin{array}{l}\text { HR is prefer to } \\
\text { RFA }\end{array}$ \\
\hline $\begin{array}{l}\text { Kutlu et } \\
\text { al. }^{4}\end{array}$ & Retrospective & $\begin{array}{c}\text { RFA }(n=437) \text { vs. } \\
\text { HR }(n=671) \text { vs. } \\
\text { LT }(n=786)\end{array}$ & Solitary $\leq 5 \mathrm{~cm}$ & $\begin{array}{l}\text { Less than } 3 \mathrm{~cm} \text { : } \\
\text { RFA=HR<LT } \\
\text { Between } 3 \text { and } 5 \mathrm{~cm} \text { : } \\
\text { RFA }<H R<L T\end{array}$ & $\begin{array}{l}\text { Better survival in HR than } \\
\text { RFA for } 3.1-3.5 \mathrm{~cm}\end{array}$ & $\begin{array}{l}\text { RFA is not } \\
\text { desirable in } \\
\text { tumor larger } \\
\text { than } 3 \mathrm{~cm}\end{array}$ \\
\hline Ng et al. ${ }^{10}$ & $\mathrm{RCT}$ & $\begin{array}{l}\text { RFA ( } n=109) \text { vs. } \\
\text { HR }(n=109)\end{array}$ & Milan criteria & $\begin{array}{l}\text { Marginally better DFS } \\
\text { in } \mathrm{HR}(P=0.072) \text {, no } \\
\text { difference in OS }\end{array}$ & - & $\begin{array}{l}\text { Prefer HR to } \\
\text { RFA }\end{array}$ \\
\hline
\end{tabular}

RCT, randomized controlled trial; RFA, radiofrequency ablation; HR, hepatic resection; ICGR15, indocyanine green retension rate at 15 min; PEI, percutaneous ethanol injection; DFS, disease-free survival; OS, overall survival; LT, liver transplantation.

\section{TREATMENT MODALITY}

\section{Radiofrequency ablation}

RFA has been applied for the patients who have poor liver function with limited tumor size up to $5 \mathrm{~cm}$ and has shown similar outcome in terms of overall and disease-free survival (DFS) in comparison to HR.' Treatment modality does not affect DFS for the patients with the tumor size smaller than $2 \mathrm{~cm}$, but the underlying parenchymal status is more important effect on long term survival. RFA is preferred if there is no survival benefit with HR because percutaneous RFA provide better post-treatment health 
related quality of life than $H R .{ }^{2}$ In a cohort study based on a Japanese nationwide survey, of 28,510 patients with HCC tumors no more than 3 tumors $(\leq 3 \mathrm{~cm})$ treated by PEI, RFA and HR, HR results in longer overall survival and better time to recurrence than either RFA or PEI. ${ }^{3}$ And in another large population based study using the Surveillance, Epidemiology and End Results database a total of 1,894 patients with HCC less than $5 \mathrm{~cm}$, it can be treated with RFA for the tumors size less than $3 \mathrm{~cm}$, survival outcome treated with RFA is worse than HR, no difference in overall survival but significant difference in DFS. Of note, for the patients with tumors measuring over $3 \mathrm{~cm}$, even small increases in tumor size $(<0.5 \mathrm{~cm})$ were found to result in significantly shorter survival for patients treated with RFA compared with those treated with HR. ${ }^{4}$ Although RFA can be successful as first line treatment with size cutoff of $2 \mathrm{~cm}, 3 \mathrm{~cm}$ and $5 \mathrm{~cm}$, the maximum tumor size for which RFA is safe and effective remains highly controversial. A $3 \mathrm{~cm}$ cutoff value has been recommended by the American Hepato-Pancreato-Biliary Association and in the Barcelona Clinic Liver Cancer staging system algorithm (Fig. 1)." There are concerns that RFA is ineffective for lesions measuring over $3 \mathrm{~cm},{ }^{2,4,5,12}$ although some reports have shown that lesions measuring up to $5 \mathrm{~cm}$ can be ablated safely. ${ }^{13-15}$ Although RFA is ineffective in larger than $3 \mathrm{~cm}$ tumor or unfavorable location, combined PEI may improve reducing recurrence in others. ${ }^{16,17}$

Microvascular invasion (MVI) is known as significant factor for disease recurrence and survival after HR. ${ }^{18,19}$ Therefore, HR may be preferred to RFA in patients with MVI. However, presence of MVI

$2 \mathrm{~cm}$ A Radiofrequency ablation

\section{Hepatic resection}

Transplantation

Figure 1. Feasibility of treatment modality according to the tumor size. Radiofrequency ablation, hepatic resection and liver transplantation (LT) can be applicable for single hepatocellular carcinoma less than $5 \mathrm{~cm}$. (A) Tumor less than $2 \mathrm{~cm}$. (B) Tumor between 2 and $3 \mathrm{~cm}$. (C) Tumor between 3 and $5 \mathrm{~cm}$. Overall survival (OS) and disease free survival (DFS) for less than $2 \mathrm{~cm}$ with radiofrequency ablation and resection is same, same OS but better DFS in 2-3 cm tumor and both OS and DFS are better with hepatic resection for 3-5 cm tumor. LT can be applicable to tumor $<5 \mathrm{~cm}$ according to the status of liver function and tumor aggressiveness. cannot be estimated preoperatively. Recent studies showed larger tumor $(>3.5 \mathrm{~cm}$ or $>5 \mathrm{~cm}$ ) and high AFP ( $>200 \mathrm{ng} / \mathrm{mL}$ or $400 \mathrm{ng} / \mathrm{mL}$ ) are significant predictable factor for presence of MVI. ${ }^{19,20}$ Therefore, tumor marker should be considered for treatment decision of small HCC as well as tumor size. In summary, RFA would be desired in patients who have small tumor (less than $3.0 \mathrm{~cm}$ ) and low $\operatorname{AFP}(<200 \mathrm{ng} / \mathrm{mL})$.

\section{Hepatic resection}

Regarding HR, the complication rate including surgical mortality rate is higher than RFA. However, it has been persistently decreased, down to less than $1 \%$ mortality, even close to zero mortality in high volume liver surgery centers. ${ }^{21,22}$ Furthermore, minimal invasive laparoscopic HR was dramatically established for last 10 years. For another issue of HR, benefit of anatomical resection in comparison to non-anatomical resection has been controversy for long time. According to the three papers based on a case control study with propensity score matching have shown no survival benefit. ${ }^{23-25}$ If it is true, hepatic surgeon may not insist to do anatomical resection better obtainable by open surgery. In apart, according to the improvement of advanced laparoscopic technique, laparoscopic anatomical resection has been well established particularly for resection more than sectionectomy, even for segmentectomy. ${ }^{26-28}$ Through gradual introduction of laparoscopic anatomical HR, the perioperative and oncological outcomes are comparable to those with open anatomical resection by experienced laparoscopic surgeon. ${ }^{29}$ For the tumors located on the surface of the liver, even though the tumor size is less than $3 \mathrm{~cm}$, local recurrence rate is high with RFA. However it is privileged indication for laparoscopic resection with enough tumor free margin. $^{30}$

In a very well-designed meta-analysis using a total of 16,103 patients to evaluate the therapeutic effects of RFA and surgical HR in the treatment of small HCC mostly $\leq 5 \mathrm{~cm}$, thirty-one studies were included in the analysis, they achieved very good conclusion in this debatable issue. Compared to the RFA group, the 3-, 5 -year overall and DFS rates in the HR group were significantly higher. In subgroup analyses, the overall and DFS in the HR group significantly higher than in the RFA group for $\mathrm{HCCS} \leq 3 \mathrm{~cm}$, whereas there was no significant difference between two groups for HCCs $\leq 2 \mathrm{~cm}$. For patients with HCCs of $2 \mathrm{~cm}$ or less, RFA is an alternative to HR because of their comparable long term efficacy remaining less procedure related complications. ${ }^{12}$ However, in small HCCs with high tumor marker, HR should be considered be- 
cause it has high recurrence risk after RFA.

\section{Liver transplantation}

LT can provide better survival outcome than RFA or HR. LT has been established and propagated as a good option showing better long-term survival benefit for the patients whose liver function is not optimal for resection, if the tumor status is within Milan criteria including solitary 2-5 cm HCC. As mentioned previously, a well-designed case control study with propensity score matching has shown no survival benefit in anatomical resection, laparoscopic resection is feasible in terms of surgical and oncologic outcomes. Furthermore it is much better for the patients in salvage liver LT later on, because it results in less adhesion and derangement of liver anatomy. A propensity score-matched case-control comparative study of laparoscopic and open resection for the HCC has shown similar short-term and long-term outcomes. ${ }^{31,32}$ Salvage living donor liver LT is significantly better survival than repeatetive HR, particularly for the Child B liver cirrhosis. ${ }^{33}$ In compensated cirrhotics with early HCC, survival rate is better with primary LT compared with HR group. And salvage LT was comparable with primary LT in terms of short and long-term outcomes. Therefore, better patients selection for the 'resection first' approach and early detection of recurrence can achieve better outcomes of the salvage LT strategy. ${ }^{34}$ Another benefit of resection first strategy is enlistment of LT for patients before recurrence at high risk of HCC recurrence after resection on the basis of pathologic aggressiveness, MVI and/or satellites nodules. ${ }^{35}$ In consideration of salvage $L T$, laparoscopic resection first strategy is a very good option, because salvage LT after laparoscopic resection is comparable to primary LT in terms of operative time, oncologic radicality, morbidity and mortality. ${ }^{36}$ On the contrary, patients with poor liver function or low level of tumor markers, RFA can be considered instead of HR in consideration of salvage LT.

\section{CONCLUSION}

RFA, HR and LT provide good outcome for patients who have small HCCs. RFA would be desired in patients who have small tumor (less than $3.0 \mathrm{~cm}$ ) and low AFP (<200 ng/mL). However, in small HCC with high tumor marker, HR should be considered. Better patients' selection for the 'resection first' approach and early detection of recurrence can achieve better outcomes of the salvage LT strategy. Another benefit of resection first strategy is en- listment of LT for patients before recurrence at high risk of HCC recurrence after resection on the basis of pathologic aggressiveness, MVI and/or satellites nodule. They should be applied appropriately according to the tumor size, location, tumor markers and underlying liver parenchymal disease. Each procedure itself of RFA, HR or LT or combination is a kind of art, and selection process of the treatment modality for individual patients to apply is another kind of art, to obtain the best short-term and long-term outcome.

\section{Authors' contributions}

Study design: Kang KJ.

Acquisition of data: Ahn KS.

Analysis and interpretation: Kang KJ.

Manuscript draft: Kang KJ.

Critical revision: Ahn KS.

Final approval: Kang KJ and Ahn KS.

\section{Funding support}

This research was supported by The Research Fund of the Korean Association for the Study of the Liver.

\section{Conflicts of Interest}

The authors have no conflicts to disclose.

\section{REFERENCES}

1. Chen MS, Li JQ, Zheng Y, Guo RP, Liang HH, Zhang YQ, et al. A prospective randomized trial comparing percutaneous local ablative therapy and partial hepatectomy for small hepatocellular carcinoma. Ann Surg 2006;243:321-328.

2. Huang G, Chen X, Lau WY, Shen F, Wang RY, Yuan SX, et al. Quality of life after surgical resection compared with radiofrequency ablation for small hepatocellular carcinomas. Br J Surg 2014;101:10061015.

3. Hasegawa K, Kokudo N, Makuuchi M, Izumi N, Ichida T, Kudo M, et al. Comparison of resection and ablation for hepatocellular carcinoma: a cohort study based on a Japanese nationwide survey. J Hepatol 2013;58:724-729.

4. Kutlu OC, Chan JA, Aloia TA, Chun YS, Kaseb AO, Passot G, et al. Comparative effectiveness of first-line radiofrequency ablation versus surgical resection and transplantation for patients with early hepatocellular carcinoma. Cancer 2017;123:1817-1827.

5. Kim GA, Shim JH, Kim MJ, Kim SY, Won HJ, Shin YM, et al. Radiofrequency ablation as an alternative to hepatic resection for single 
small hepatocellular carcinomas. Br J Surg 2016;103:126-135.

6. Huang J, Yan L, Cheng Z, Wu H, Du L, Wang J, et al. A randomized trial comparing radiofrequency ablation and surgical resection for HCC conforming to the Milan criteria. Ann Surg 2010;252:903-912.

7. Feng K, Yan J, Li X, Xia F, Ma K, Wang S, et al. A randomized controlled trial of radiofrequency ablation and surgical resection in the treatment of small hepatocellular carcinoma. J Hepatol 2012;57:794802.

8. Fang $Y$, Chen W, Liang $X$, Li D, Lou H, Chen R, et al. Comparison of long-term effectiveness and complications of radiofrequency ablation with hepatectomy for small hepatocellular carcinoma. J Gastroenterol Hepatol 2014;29:193-200.

9. Imai K, Beppu T, Chikamoto A, Doi K, Okabe H, Hayashi H, et al. Comparison between hepatic resection and radiofrequency ablation as first-line treatment for solitary small-sized hepatocellular carcinoma of $3 \mathrm{~cm}$ or less. Hepatol Res 2013;43:853-864.

10. Ng KKC, Chok KSH, Chan ACY, Cheung TT, Wong TCL, Fung JYY, et al. Randomized clinical trial of hepatic resection versus radiofrequency ablation for early-stage hepatocellular carcinoma. Br J Surg 2017;104:1775-1784.

11. Bruix J, Sherman M; American Association for the Study of Liver Diseases. Management of hepatocellular carcinoma: an update. Hepatology 2011;53:1020-1022.

12. Xu Q, Kobayashi S, Ye X, Meng X. Comparison of hepatic resection and radiofrequency ablation for small hepatocellular carcinoma: a meta-analysis of 16,103 patients. Sci Rep 2014;4:7252.

13. Peng ZW, Zhang YJ, Chen MS, Lin XJ, Liang HH, Shi M. Radiofrequency ablation as first-line treatment for small solitary hepatocelIular carcinoma: long-term results. Eur J Surg Oncol 2010;36:10541060.

14. Cho YK, Rhim H, Noh S. Radiofrequency ablation versus surgical resection as primary treatment of hepatocellular carcinoma meeting the Milan criteria: a systematic review. J Gastroenterol Hepatol 2011;26:1354-1360.

15. Gravante G, Overton J, Sorge R, Bhardwaj N, Metcalfe MS, Lloyd $D M$, et al. Radiofrequency ablation versus resection for liver tumours: an evidence-based approach to retrospective comparative studies. J Gastrointest Surg 2011;15:378-387.

16. Chen S, Peng Z, Lin M, Chen Z, Hu W, Xie X, et al. Combined percutaneous radiofrequency ablation and ethanol injection versus hepatic resection for $2.1-5.0 \mathrm{~cm}$ solitary hepatocellular carcinoma: a retrospective comparative multicentre study. Eur Radiol 2018;28:36513660.

17. Shi F, Tan Z, An H, Wang X, Xu Y, Wang S. Hepatocellular carcinoma $\leq 4 \mathrm{~cm}$ treated with radiofrequency ablation with or without percutaneous ethanol injection. Ann Hepatol 2016;15:61-70.

18. Roayaie S, Blume IN, Thung SN, Guido M, Fiel MI, Hiotis S, et al. A system of classifying microvascular invasion to predict outcome after resection in patients with hepatocellular carcinoma. Gastroenterology 2009;137:850-855.

19. Zhao H, Hua Y, Lu Z, Gu S, Zhu L, Ji Y, et al. Prognostic value and preoperative predictors of microvascular invasion in solitary hepatocellular carcinoma $\leq 5 \mathrm{~cm}$ without macrovascular invasion. Oncotarget 2017;8:61203-61214.

20. Zhao WC, Fan LF, Yang N, Zhang HB, Chen BD, Yang GS. Preoperative predictors of microvascular invasion in multinodular hepatocellular carcinoma. Eur J Surg Oncol 2013;39:858-864.

21. Yoon YI, Kim KH, Kang SH, Kim WJ, Shin MH, Lee SK, et al. Pure laparoscopic versus open right hepatectomy for hepatocellular carcinoma in patients with cirrhosis: a propensity score matched analysis. Ann Surg 2017;265:856-863.

22. Buell JF, Thomas MT, Rudich S, Marvin M, Nagubandi R, Ravindra $\mathrm{KV}$, et al. Experience with more than 500 minimally invasive hepatic procedures. Ann Surg 2008;248:475-486.

23. Okamura Y, Ito T, Sugiura T, Mori K, Uesaka K. Anatomic versus nonanatomic hepatectomy for a solitary hepatocellular carcinoma: a case-controlled study with propensity score matching. J Gastrointest Surg 2014;18:1994-2002.

24. Ishii M, Mizuguchi $T$, Kawamoto $M$, Meguro $M$, Ota $S$, Nishidate $T$, et al. Propensity score analysis demonstrated the prognostic advantage of anatomical liver resection in hepatocellular carcinoma. World J Gastroenterol 2014;20:3335-3342.

25. Marubashi S, Gotoh K, Akita H, Takahashi H, Ito Y, Yano M, et al. Anatomical versus non-anatomical resection for hepatocellular carcinoma. Br J Surg 2015;102:776-784.

26. Sugioka A, Kato Y, Tanahashi Y. Systematic extrahepatic Glissonean pedicle isolation for anatomical liver resection based on Laennec's capsule: proposal of a novel comprehensive surgical anatomy of the liver. J Hepatobiliary Pancreat Sci 2017;24:17-23.

27. Machado MAC, Surjan R, Basseres T, Makdissi F. Laparoscopic parenchymal-sparing liver resections using the intrahepatic Glissonian approach. Ann Surg Oncol 2017;24:2353-2354.

28. Jang JY, Han HS, Yoon YS, Cho JY, Choi Y, Lee W, et al. Threedimensional laparoscopic anatomical segment 8 liver resection with Glissonian approach. Ann Surg Oncol 2017;24:1606-1609.

29. Ryu T, Honda G, Kurata M, Kobayashi S, Sakamoto K, Honjo M. Perioperative and oncological outcomes of laparoscopic anatomical hepatectomy for hepatocellular carcinoma introduced gradually in a single center. Surg Endosc 2018;32:790-798.

30. Ito T, Tanaka S, Iwai S, Takemura S, Hagihara A, Uchida-Kobayashi S, et al. Outcomes of laparoscopic hepatic resection versus percutaneous radiofrequency ablation for hepatocellular carcinoma located at the liver surface: a case-control study with propensity score matching. Hepatol Res 2016;46:565-574.

31. Ahn KS, Kang KJ, Kim YH, Kim TS, Lim TJ. A propensity scorematched case-control comparative study of laparoscopic and open 
Keun Soo Ahn, et al. RFA, resection or transplantation for small HCC

liver resection for hepatocellular carcinoma. J Laparoendosc Adv Surg Tech A 2014;24:872-877.

32. Han HS, Shehta A, Ahn S, Yoon YS, Cho JY, Choi Y. Laparoscopic versus open liver resection for hepatocellular carcinoma: case-matched study with propensity score matching. J Hepatol 2015;63:643-650.

33. Yamashita Y, Yoshida Y, Kurihara T, Itoh S, Harimoto N, Ikegami T, et al. Surgical results for recurrent hepatocellular carcinoma after curative hepatectomy: repeat hepatectomy versus salvage living donor liver transplantation. Liver Transpl 2015;21:961-968.

34. Bhangui P, Allard MA, Vibert E, Cherqui D, Pelletier G, Cunha AS, et al. Salvage versus primary liver transplantation for early hepatocel- lular carcinoma: do both strategies yield similar outcomes? Ann Surg 2016;264:155-163.

35. Ferrer-Fàbrega J, Forner A, Liccioni A, Miquel R, Molina V, Navasa M, et al. Prospective validation of ab initio liver transplantation in hepatocellular carcinoma upon detection of risk factors for recurrence after resection. Hepatology 2016;63:839-849.

36. Felli E, Cillo U, Pinna AD, De Carlis L, Ercolani G, Santoro R, et al. Salvage liver transplantation after laparoscopic resection for hepatocellular carcinoma: a multicenter experience. Updates Surg 2015;67:215-222. 